\title{
PENINGKATAN KUALITAS HIDUP MANUSIA BERDASAR MATIUS 23:39 MELALUI PEMBANGUNAN GEDUNG SEKOLAH DI DUSUN BONENGGAYA KECAMATAN RIO PAKAVA KABUPATEN DONGGALA SULAWESI TENGAH
}

\author{
Tony Salurante ${ }^{1}$ Malik $^{2}$ Riswan $^{3}$ dan Eni Karlina Wau ${ }^{4}$ \\ Sekolah Tinggi Teologi Injili Arastamar (SETIA) Jakarta \\ Email: tony.salurante@sttsetia.ac.id
}

\begin{abstract}
ABSTRAK
Peningkatan taraf hidup umat manusia dan suatu bangsa adalah pintu gerbang peradaban mereka menuju kepada suatu kemajuan. Setidaknya ada indikator pencapaian pembangunan suatu masyarakat agar dapat berkembang dan maju dalam segala lini kehidupan. Indikator pembangunan tersebut adalah empat pilar peradaban yaitu; kehidupan Sosial, Pendidikan, Spiritual dan perekonomian. Namun bagaimana hal ini diwujudkan jika masih ada daerah-daerah terpencil yang belum terjangkau oleh salah indikator pilar peradaban tersebut? Inilah yang menjadi tujuan penelitian ini untuk mengangkat suatu realita yang fenomenal tentang kehidupan masyarakat yang terpinggirkan dan terlupakan yakni masyarakat Bonenggaya. Degan menggunakan metode pendekatan sosial budaya dalam bentuk komunitas untuk mencapai tujuan yang mencerdaskan kehidupan bangsa dengan mendirikan gedung sekolah bagi masyarakat ini. Sebagai hasil dari penelitian ini bahwa seluruh lapisan masyarakat Bonenggaya menerima rencana pembangunan Gedung sekolah serta tenaga pengajar dari SETIA Jakarta untuk tinggal di daerah mereka melaksanakan pembelajaran sampai waktu yang tidak ditentukan.
\end{abstract}

Kata kunci: Bonenggaya; Pendidikan; Missio Dei, Sosial-budaya.

\section{PENDAHULUAN}

Amanat Garis-garis Besar Haluan Negara (GBHN) dalam mencerdaskan kehidupan bangsa menjadi tugas dan tanggung jawab seluruh warga negara Republik Indonesia. Oleh sebab itu Sekolah Tinggi Teologi Injili Arastamar (selanjutnya sebut SETIA) Jakarta merasa terpanggil untuk ikut berpartisipasi dalam mewujudkan amanat GBHN tersebut. Dorongan cinta kasih dan kepedulian terhadap sesama maka sejak tahun 2017 mahasiswa dan alumni dari SETIA Jakarta mengabdikan diri menjadi pelayan Tuhan di masyarakat Bonenggaya. Salah satu cara adalah menjadi guru bagi masyarakat Bonenggaya diawali dengan pola pendekatan kultural yang melahirkan suatu keakraban. Tujuan utama dalam penelitian ini adalah untuk mendidik masyarakat menjadi manusia yang seutuhnya. Dalam Pendidikan selain guru, sarana dan prasarana seperti gedung dan buku-buku merupakan hal yang sentral untuk mendapatkan hasil

\footnotetext{
${ }^{1}$ Dosen PAK dan Teologi Sekolah Tinggi Teologi Injili Arastamar (SETIA) Jakarta

${ }^{2}$ Dosen Master Teologi Sekolah Tinggi Teologi Injili Arastamar (SETIA) Jakarta

${ }^{3}$ Mahasiswa Prodi Pendidikan Agama Kristen

${ }^{4}$ Guru (alumni) Sekolah Tinggi Teologi Injili Arastamar (SETIA) Jakarta
} 
yang maksimal. Karena seluruh masyarakat yang jumlah 250 jiwa bersedia untuk menerima keberadaan guru dan rohaniawan maka metode yang dipakai dalam PkM ini adalah hidup dalam komunitas.

\section{METODE PENELITIAN}

Metode yang digunakan dalam teologi praksis ini dengan menggunakan pendekatan sosialkultural. Mahasiswa dan alumni yang diutus diharapkan mampu membangun kepercayaan dan ikatan emosional dengan tokoh masyarakat dan penduduk lokal. Dengan mengikuti arahan dari dosen-dosen maka terjalin kerjasama yang saling menopang penelitian ini. Setelah mereka mendapat penugasan dari SETIA Jakarta, kemudian mengadakan survei ke lokasi. Minta izin ke pemerintah setempat, mengadakan pendekatan kepada masyarakat dan pemerintah setempat, sosialisasi kegiatan kepada masyarakat setempat, membangun strategi setelah itu melaksanakan kegiatan misi dengan metode pendekatan sosial budaya dan literasi.

\section{HASIL DAN PEMBAHASAN}

Dusun Bonenggaya merupakan bagian dari desa Pakava, Kecamatan Rio Pakava yang terletak di Kabupaten Donggala Sulawesi Tengah, kecamatan ini memiliki luar wilayah sebesar luas wilayah $872,16 \mathrm{~km}^{2}$. Secara umum beberapa dusun yang terdapat di kecamatan ini berada di daerah pegunungan-pegunungan. Dusun tersebut dihuni oleh 47 KK dan anak-anak sekitar 46 anak-anak. Masyarakat di dusun Bonenggaya dan sekitarnya hidup terasing dari perkotaan. Sebagian besar orang dewasa tidak berpendidikan dan buta huruf. Hanya 10 orang dewasa yang bisa berbahasa Indonesia yaitu: Gatu, Bama, Muso, Gai, Uji, Songgi, Pako dan Sora (data 2017). Demikian anak-anak mereka dengan kesehatan dan gizi yang cukup memprihatinkan. Sehari-hari mereka berkebun dengan mengandalkan curah hujan. Bentuk rumah yang sangat sederhana dan tergolong masih primitif menjadikan kehidupan mereka terisolir dari masyarakat luar. Sangat mengherankan jika masih ada daerah yang tertinggal seperti ini padahal mereka berada tepat diperbatasan Sulawesi Tengah yaitu kabupaten Donggala dengan Sulawesi Barat yakni kabupaten Mamuju Utara.

Corak kehidupan yang tersisihkan tersebut, tentu menyisakan masalah sosial seperti Pendidikan, ekonomi dan spiritual. Fenomena ini mengindikasikan bahwa empat pilar pembangunan manusia seutuhnya belum menyentuh kehidupan masyarakat Bonenggaya ini yakni; Kehidupan Sosial, Pendidikan dan Ekonomi dan spiritual. Jika dilihat dari faktor yuridisnya, maka tentu ini adalah tanggung jawab penuh oleh pemerintah, namun jika dilihat dari faktor moralnya, maka ini adalah tanggung jawab bersama pemerintah dan rakyat termasuk instansi Pendidikan untuk menuntaskan masalah tersebut. Oleh sebab itu untuk dapat mewujudkan keempat pilar ini, maka sebagai starting point yang diambil oleh peneliti adalah pilar sosial. Kehidupan bermasyarakat adalah langkah awal untuk masuk dalam kehidupan mereka. Hal ini merupakan metode pendekatan yang paling praktis dan strategis untuk menjangkau masyarakat di daerah ini, setelah itu pendekatan melalui kehidupan Pendidikan, ekonomi dan spiritual dapat dikerjakan.

Pendekatan literasi merupakan komunikasi ampuh dalam mengadakan sosialisasi kepada kelompok atau komunitas apapun. Untuk itu pada penelitian ini tim peneliti akan membahas secara singkat tentang literasi tersebut terkhusus apa yang disebut dengan literasi data. Literasi 
data adalah kemampuan untuk membaca, menganalisis dan menggunakan informasi di dunia digital. Untuk memasuki fase ini maka hal ini sangat jauh berbeda dengan kehidupan masyarakat Bonenggaya karena dapat dikatakan pola hidup mereka yang masih primitif ${ }^{5}$ sebelum dijangkau oleh pelayanan para hamba Tuhan. Dengan kehadiran peneliti bersama tim di sana dapat memberikan pengetahuan literasi kepada mereka seperti berbahasa Indonesia, membaca dan menulis bagi anak-anak mereka.

Setelah memahami apa itu literasi data, maka dipandang perlu juga memahami literasi teknologi. Tentu hal ini bersinggungan dengan salah satu pilar pembangunan sebagaimana disebutkan di atas. Literasi teknologi adalah suatu kemampuan untuk memahami cara kerja mesin dan aplikasi teknologi. Hal ini juga perlu diperkenalkan kepada masyarakat manapun agar mereka memahami bahkan dapat menggunakan teknologi secara tepat guna. Literasi berikutnya adalah literasi manusia dimana literasi manusia ini adalah suatu kemampuan manusia untuk memahami aspek humanities, komunikasi dan desain. Jika hal ini tidak dilakukan maka akan sangat timpang apa yang disebut dalam empat pilar pembangunan itu, karena kemampuan manusia dalam berkomunikasi satu sama lain. Maka literasi manusia ini sangat perlu untuk dipahami agar kehidupan masyarakat Bonenggaya tidak merasa tersisih dari dunia luar. Sejak awal kehadiran kami masyarakat sangat antusias dan bersemangat untuk melakukan berbagai hal baru. Bahkan kehadiran kami disambut dengan sangat baik ditengah-tengah masyarakat yang mayoritas belum bisa berbahasa Indonesia dengan baik. Namun karena kami selalu bersama berada di dusun tersebut maka rintangan dalam masalah Bahasa dapat terselesaikan, sekalipun perlu ada penterjemahan yang selalu membantu.

\begin{tabular}{|c|c|c|}
\hline Usia & $\begin{array}{c}\text { Awal } \\
\text { (yang buta huruf) }\end{array}$ & $\begin{array}{c}\text { Setelah } \\
\text { (bisa membaca dan Berhitung) }\end{array}$ \\
\hline 3-5 Tahun & 30 Jiwa (0\%) & $\begin{array}{l}30 \text { anak (mengenal huruf dan } \\
\text { bernyanyi } 50 \% \text { ) }\end{array}$ \\
\hline 6-12 Tahun & 57 Orang $(0 \%)$ & 57 Jiwa (60\%) \\
\hline $\begin{array}{l}\text { Pemuda/- } \\
\text { Pemudi }\end{array}$ & $\begin{array}{l}25 \text { Orang (hanya 5\% yang } \\
\text { bisa membaca) }\end{array}$ & $\begin{array}{l}25 \text { Orang (hanya } 90 \% \text { yang bisa } \\
\text { membaca) }\end{array}$ \\
\hline Orangtua & 10 Orang (\%) & 25 orang (50 \%) \\
\hline Lulus SD & $0 \%$ & 25 orang \\
\hline
\end{tabular}

Tabel 1.1 Hasil analisis sebelum dan sesudah ada Gedung dan sarana Sekolah

Dalam misi penjangkauan bagi masyarakat Bonenggaya, sangat perlu untuk memperlengkapi hamba Tuhan yang akan diutus ke daerah tersebut. Perlengkapan di sini adalah bagaimana mereka belajar tentang budaya hidup masyarakat di sana. Berbicara tentang kebudayaan adalah berbicara tentang seluruh pola hidup masyarakat. Oleh sebab itu sangat perlu bagi para pelayan untuk

${ }^{5}$ Sebelumnya ada pelayan yang menjangkau daearah ini, namun mereka tidak bisa bertahan hidup dengan situasi masyarakat setempat akhirnya hamba Tuhan tersebut meninggalkan mereka, hal ini menjadikan masyarakat ini kembali lagi ke pola kehidupan yang lama. 
diperlengkapi dengan kemampuan yang cukup mengenai daerah yang akan ia layani. Perlengkapan ini berbicara tentang pengetahuan kebudayaan masyarakat Bonenggaya, suatu pola hidup mereka. Begitu juga budaya kepercayaan mereka yang perlu diketahui oleh setiap pelayan misi. Perlengkapan yang menjadi jembatan komunikasi bagi masyarakat adalah Bahasa. Belajar bahasa daerah Bonenggaya akan memudahkan bagi pelayan untuk menjangkau mereka. Begitu banyak kendala yang dihadapi oleh setiap hamba Tuhan dalam pelayanan karena faktor bahasa.

Perlengkapan dalam pengetahuan akan Bahasa ini saya sebut sebagai literasi misi dalam menerjemahkan Alkitab ke dalam bahasa daerah. Secara khusus, Bahasa daerah Bonenggaya yang merupakan rumpun suku Kaili Da'a di kabupaten Donggal Sulawesi Tengah. Materi perlengkapan ini bertujuan untuk mempersiapkan para hamba Tuhan yang diutus ke Bonenggaya agar tidak mati gaya ketika sampai di pelayanan. Mengapa dikatakan mati gaya? Karena daerah itu masuh sangat terisolir. Maka diperlukan suatu persiapan yang kreatif, inovatif, edukatif dan aplikatif. Dengan modal kesiapan ini yang ditopang dengan dasar iman yang kuat akan menjadikan panggilan ini menjadi sangat berarti bagi masyarakat Bonenggaya.

Pengutusan adalah suatu hal yang sudah menjadi ketetapan surga dalam pelaksanaan misi di seluruh muka bumi ini. Panggilan untuk pergi ke semua suku bangsa dan bahasa di muka bumi merupakan panggilan khusus bagi setiap orang percaya untuk pergi menjadi saksi Kristus. Hal ini sudah disampaikan oleh Kristus bagi para murid-Nya sebelum Ia terangkat ke Surga. Makus menuliskan perkataan Yesus tersebut demikian; Akhirnya Ia menampakkan diri kepada kesebelas orang itu ketika mereka sedang makan, dan Ia mencela ketidakpercayaan dan kedegilan hati mereka, oleh karena mereka tidak percaya kepada orang-orang yang telah melihat Dia sesudah kebangkitan-Nya. Lalu Ia berkata kepada mereka: "Pergilah ke seluruh dunia, beritakanlah Injil kepada segala makhluk. Siapa yang percaya dan dibaptis akan diselamatkan, tetapi siapa yang tidak percaya akan dihukum (Mrk. 16:14-16). Pengutusan hamba Tuhan merurpakan legitimasi yang sahih bagi pelayanan mereka. Oleh sebab itu dalam pengutusan perlu ada pihak yang mendukung baik dukungan moriil dan materiil serta spirituiil. Pengutusan hamba Tuhan ke daerah Bonenggaya dilakukan dengan melihat komitmen total baik yang diutus maupun pihak yang mengutus. Komitmen total ini berkaitan dengan jaminan hidup para hamba Tuhan yang melayani di sana nanti. Sebab daerah tersebut masih tertinggal dari pola pertanian yang modern, dengan gaya bertani yang masih berpindah-pindah. Dengan demikian sangat diperlukan dukungan materiil sebagai jaminan hidup mereka disana.

To reach unreached people ini adalah motto Sekolah Tinggi Teologi Injili Arastamar Jakarta. Motto ini sudah sangat familiar dalam pelayanan dan motto ini juga yang menjadi acuan penelitian ini. Menjangkau yang tidak terjangkau dan melayani yang tidak terlayani itulah prinsip dan motto pelayanan yang semestinya menjadi barometer dalam pelayanan. Mengapa mejangkau masyarakat Bonenggaya, karena mereka belum terjangkau, mereka masih tertinggal, mereka tidak terlayani dari berbagai aspek hidup manusia. Salah satu target dalam pelaksanaan misi adalah bagaimana menjangkau suatu daerah agar dapat melayani mereka melalui Injil Kristus. Setelah memperlengkapi para hamba Tuhan untuk menjangkau suatu daerah maka akan diadakan pengutusan untuk menjangkau daerah tertentu seperti peneliti menjangkau daerah Bonenggaya ini. Menjangkau daerah ini adalah suatu pergumulan karena melalui suatu medan yang agak sulit. Selain kesulitan bahasa juga kehidupan nomaden menjadi kendala bagi penjangkauan masyarakat ini. Pola hidup yang tergolong primitif menjadi kesulitan bagi masyarakat luar untuk 
berkomunikasi dengan masyarakat Bonenggaya. Oleh sebab itu Sekolah Tinggi Teologi Injili Arastamar (SETIA) Jakarta terpanggil untuk menjangkau masyarakat Bonenggaya ini.

Metode penjangkauan bagi masyarakat Bonenggaya yang telah dilakukan oleh SETIA Jakarta adalah hamba Tuhan harus tinggal di antara mereka sehingga pola hidup tinggal Bersama dalam suatu lokasi akan mempengaruhi pola hidup mereka yang masih tinggal dalam hutan. Berikut yang dilakukan sebagai penjangkauan rohani mereka adalah dengan mendirikan rumah ibadah hal ini secara tidak langsung akan mengajak mereka untuk tinggal dan bermukim di sekitar Gedung gereja. Sebagai perwujudan panggilan negara yang tertuang dalam amanat UUD, 45 dan GBHN yakni mencerdaskan kehidupan bangsa dan negara Republik Indonesia, maka dalam penelitian ini disampaikan bahwa telah didirikan gedung sekolah tingkat Dasar di kampung Bonenggaya. Hal ini disambut dengan antusias warga masyarakat Bonenggaya, selain pendirian gedung sekolah diberikan juga tenaga pengajar untuk mengajar mereka dan menetap di sana. Sudah menjadi rahasia umum jika banyak guru-guru zaman sekarang ini yang tidak bertahan tinggal mengajar di daerah terpencil apalagi di daerah hutan seperti Bonenggaya, namun dalam penjangkauan hamba Tuhan SETIA dan GKSI masih tetap ada dan bersedia melayani mereka, meskipun jauh dari keramaian kota. Di sana kami menempatkan dua tenaga pendidik sekaligus rohaniawan yakni; Adolfina dan Eni Karlina Wau. Mereka berdua sebagai alumni SETIA Jakarta yang berkomitmen untuk menuntaskan buta aksara bagi masyarakat Bonenggaya.

Kesulitan penjangkauan hamba Tuhan sebelumnya adalah karena tidak mendapat dukungan dari berbagai pihak dan hal ini menjadikan masyarakat Bonenggaya kembali hidup seperti dulu lagi. Oleh sebab itu dalam penjangkauan kali ini dipandang perlu dukungan bagi hamba Tuhan untuk tinggal dan menetap di antara masyarakat Bonenggaya. Dukungan fasilitas bagi mereka agar dapat bertahan di tengah kehidupan masyarakat Bonenggaya tersebut dapat berupa tinggal tinggal serta jaminan hidup mereka setiap bulan terus berjalan. Hal ini dapat menopang keberlangsungan pelayanan di Bonenggaya sehingga tetap berjalan dan berkesinambungan.

Untuk dapat beradaptasi dengan daerah Bonenggaya ini membutuhkan kesabaran, hal itu dapat dilihat dari faktor budaya hidup yang berbeda dan ditunjang bahasa yang juga belum memahami bahasa Indoenesia. Ketika peneliti masuk daerah ini maka harus didampingi seorang penerjemah, karena mereka tidak mengerti apa yang peneliti sampaikan demikian juga peneliti tidak mengerti apa yang mereka sampaikan jika tidak ada penerjemah. Itulah dalam bagian strategi di atas, bahwa adalah sangat perlu memperlengkapi hamba Tuhan untuk belajar bahasa daerah yang akan dijangkau. Pola persiapan seperti ini sudah dilakukan para misionaris untuk menjangkau daerah tertentu salah satu contohnya adalah Nommensen yang mempersiapkan diri dengan belajar bahasa Batak di Padang Sumatera Barat sebelum memasuki daerah Batak tersebut. Sebagai hasil dari pelayanan Nommensen hampir seluruh tanah Batak menjadi Kristen (Malik, Diktat SGI 2019).

Membangun fasilitas Pendidikan sebagai terobosan baru untuk membuka peradaban baru bagi masyarakat Bonenggaya. Langkah untuk masuk dalam pilar Pendidikan sebagaimana tertuang dalam GBHN yakni membangun manusia Indonesia seutuhnya dalam mencerdaskan kehidupan bangsa, maka SETIA Jakarta merasa terpanggil dan tergerak untuk mendirikan gedung sekolah bagi masyarakat Bonenggaya ini. Alhasil dari kerinduan tersebut dapat tercapai dan puji Tuhan, sekarang sudah berdiri Gedung sekolah Dasar di Bonenggaya yang walaupun masih dikelolah oleh pihak Yayasan SABAS Jakarta, namun hal itu tidak mengurangi antusiasme masyarakat Boneggaya 
untuk mendukung kegiatan ini. Hampir semua anak-anak mereka disuruh untuk masuk sekolah, disamping itu juiga mengajar orangtua yang mau belajar di pastori. Peluang pendektan Pendidikan kepada masyarakat ini adalah dengan menggunakan istilah jemput bola. Jika mereka tidak ada yang mencari gedung belajar, maka kita yang mencari mereka untuk diajar. Inilah pola pengajaran Yesus, dimana Ia mencari para murid tidak hanya disatu tempat dan latar belakang kehidupan, namun di berbagai tempat dan latar belakang kehidupan. Ada yang dari Nelayan, ada yang tukang pajak dan sebagainya. Metode Pendidikan yang diajarkan dalam masyarakat ini tentu menyesuaikan dengan budaya mereka, agar maksud dan tujuan Pendidikan dapat tercapai secara maksimal. Akhirnya pada tanggal 22 September pelaksanaan Pendidikan dengan pemakaian Gedung sekolah yang baru dibuka dengan resmi oleh peneliti selaku utusan dari Yayasan SABAS dan SETIA Jakarta. Hadir juga dalam kegiatan ini kepala Desa setempat Bersama para aparatnya, begitu juga beberapa kepala dusun sekkitar Bersama para tokoh adat dan pimpinan gereja sekitar. Ini adalah suatu dukungan moriiil bagi pelayanan dan pelaksanaan Pendidikan di tempat ini.

Berkolaborasi dengan gereja pendukung Misi dalam menjangkau daerah ini sangat diperlukan. Mejangkau daerah ini tentu sangat membutuhkan dukungan moriil bagi para pelayan atau tenaga pengajar sekolah di Bonenggaya. STT SETIA didukung oleh Gereja Kristen Indonesia (GKI) yang berpusat di Jakarta ikut terlibat dalam dukungan finansial bagi pengajar di Bonenngaya. Begitu juga kelompok hamba Tuhan yang bergabung dalam Yayasan G12 yang telah beberapa kali datang mengunjungi daerah ini. Kolaborasi ini tentu sangat signifikan bagi pelayanan misi Pendidikan di pedalaman dan itulah yang dilakukan oleh SETIA Jakarta. SETIA menyediakan tenaga pengajar, sementara kelompok yang lain mendukung dalam doa dan dana. Tentu saja SETIA punya tanggung jawab moral untuk menjaga amanat ini dengan selalu memperhatikan penggunaan dana tersebut. Hal ini membutuhkan akuntabilitas dan relialibitas dari setiap pengguna dukungan bantuan tersebut.

Kesinambungan pendidikan di Bonenggaya sangat ditentukan juga oleh tenaga pendidik yang memiliki komitmen total untuk mengajar di daerah ini. Itulah sebabnya SETIA Jakarta selain mengutus tenga pengajar yang tetap, juga mengutus mahasiswa praktikum selama satu (1) tahun untuk membantu pelayanan Pendidikan di tempat ini. Dengan demikian pengajaran akan tetap berjalan secara konsisten dan berkesinambungan. Pelayanan Pendidikan merupakan tonggak sejarah babak baru bagi masyarakat ini dimana dengan Pendidikan tersebut secara otomatis akan membuka cakrawala pemikiran mereka tentang dunia ini dan kehidupan mereka tentang Sang Pencipta. Kesadaran akan keberadaan sang Pencipta menjadi pintu gerbang bagi pengenalan akan Allah serta pertumbuhan iman yang benar kepada Tuhan. Hal ini selaras dengan kebenaran Firman Tuhan yang disampaikan oleh Paulus kepada jemaat Tuhan di Roma demikian; Tetapi bagaimana mereka dapat berseruh kepada-Nya, jika mereka tidak percaya kepada-Nya? Bagaimana mereka dapat percaya kepada Dia, jika mereka tidak mendengar tentang Dia? Bagaiamana mereka mendengar tentang Dia, jika tidak ada yang memberitakan-Nya? Dan bagaimana mereka dapat memberitakan-Nya, jika mereka tidak diutus? Seperti ada tertulis: Betapa indahnya kedatangan mereka yang membawa kabar baik! (Rm. 10:14-15). Interpretasi ayat ini menjadi landasan pacu bagi pelayanan kepada semua suku bangsa dalam konteks pelayanan misi Agung Kristus yang tidak hanya menyelamatkan, namun juga memberikan hikmat yaitu kecerdasan dan kecerdasan tersebut akan dapat terealisasi dengan adanya PENDIDIKAN. Sungguh indah kedatangan mereka yang membawa kabar baik. Kabar baik (good news) dalam arti luas adalah juga memberikan ruang yang 
layak bagi manusia ciptaan Allah agar dapat mengenal Allah dan alam sekitarnya. Dapat dibayangkan jika masyarakat Bonenggaya ini hidup tertutup dengan dunia luar, maka betapa sempitnya dunia bagi mereka. Mereka hidup dalam bayang-bayang ketakutan sehingga mereka berpindah-pindah tempat tinggal (nomaden). Mereka tidak memiliki kepastian hidup, sebab bagi mereka yang kuatlah yang berkuasa itulah hukum rimba yang menjadi hukum mereka. Sebagai kabar baiknya masyarakat Bonenggaya dapat menerima tawaran pelayanan dari SETIA Jakarta sehingga Langkah-langkah pembangunan dapat dilaksanakan bagi mereka secara khusus pembangunan gedung sekolah. Sebagai apresiasi para mitra pendukung pelayanan di Bonenggaya ini dengan pendirian gedung sekolah tersebut, mereka membantu sepenuhnya biaya pembangunan sekolah tersebut dan setelah peresmian gedung sekolah tersebut para mitra pendukung juga menyumbangkan seragam Sekolah Dasar bagi anak-anak yang akan masuk sekolah. Sungguh indah kedatangan mereka yang membawa kabar baik.

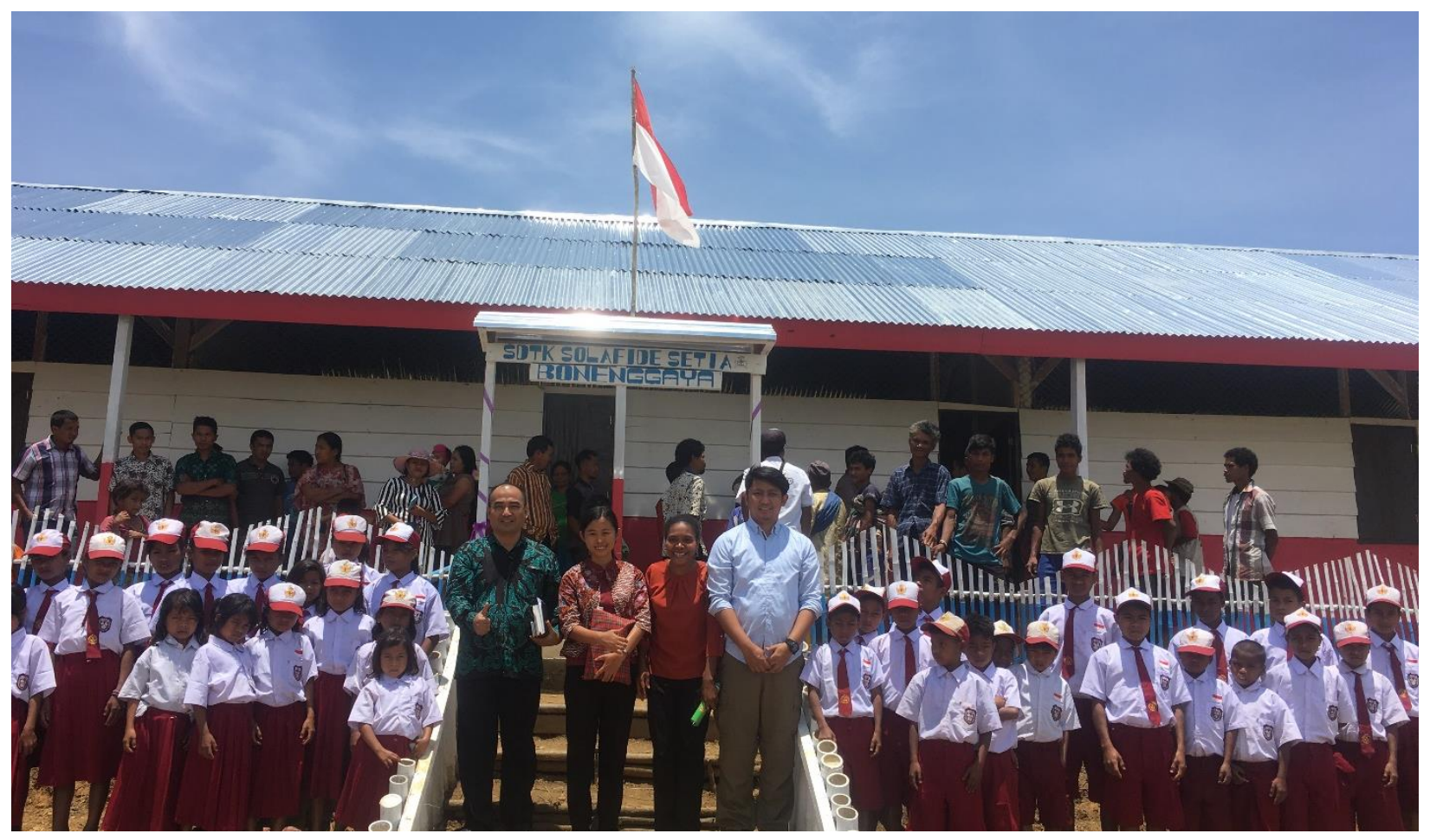

Gambar 1. Malik, Eni Karlina, Adolfina, dan Tony Salurante bersama siswa-siswi di Bonengggaya 


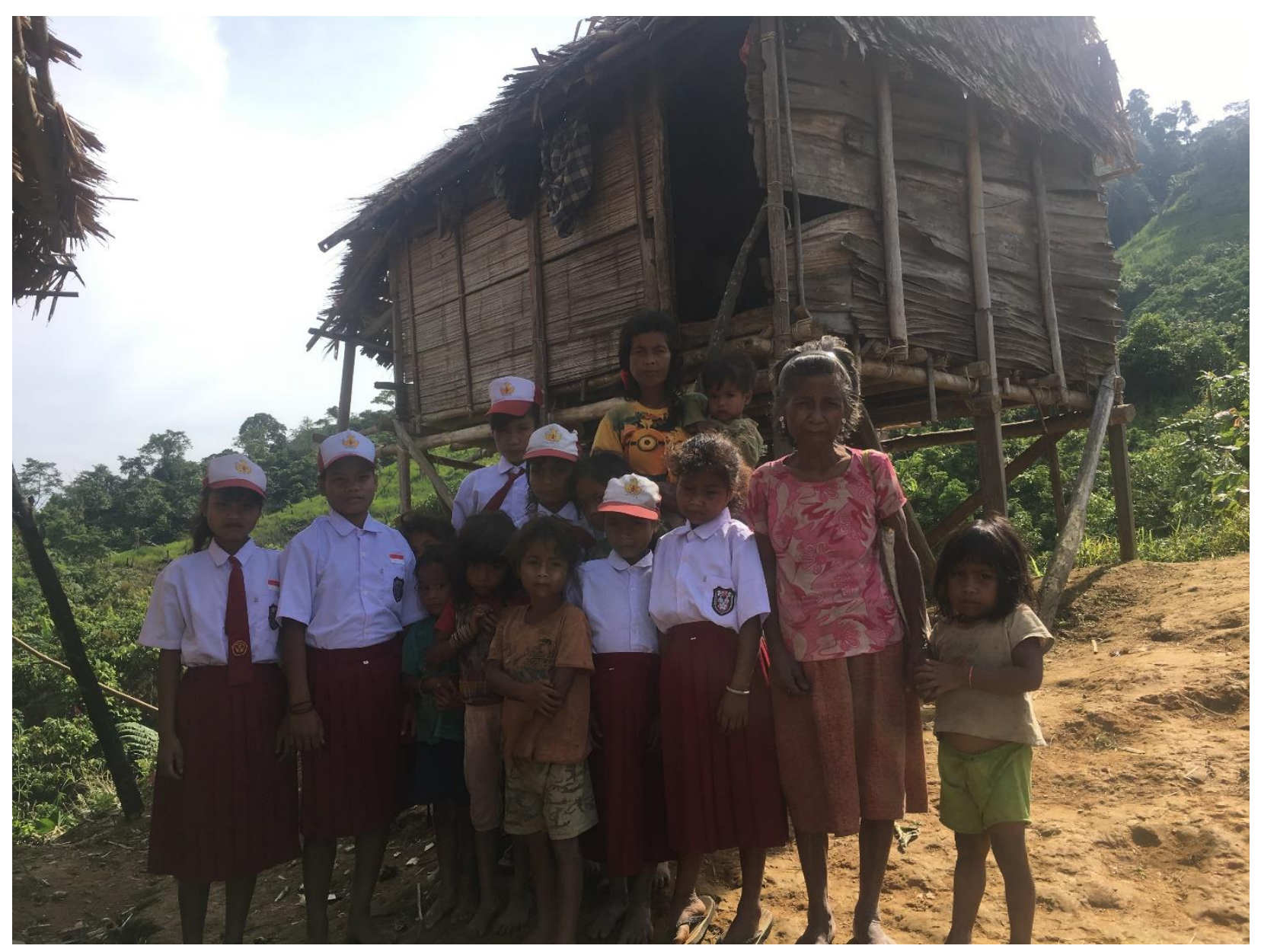

\section{Gambar 2. Siswi-siswi yang sudah mendapatkan seragam sekolah}

\section{KESIMPULAN}

Pendirian Gedung Sekolah dan kehadiran Guru di Dusun Bonenggaya telah memberi banyak perubahan positif yang sangat signifikan. Dengan semakin banyak anak-anak yang bersekolah semakin banyak yang bisa membaca dan menulis. Perubahan pola hidup, pengetahuan yang bertambah. Ini semua merupakan tahap awal menuju pembaharuan hidup dan wujud saling mengasihi sesama manusia.

\section{UCAPAN TERIMAKASIH}

Program PkM di Dusun Bonenggaya ini dapat terselenggara karena dukungan dari beberapa pihak seperti Yayasan G12, Gereja Kristen Setia Indonesia, Gereja Kristen Imanuel-Hosana dan Gereja Kristen Indonesia Jemaat Gunung Sahari. Ucapana Puji Syukur untuk dukungannya sampai dengan saat ini sehingga masyarakat sudah mengalami banyak perubahan. Begitu juga dengan Badan Pengurus Wilayah GKSI Donggala, Camat Rio Pakava dan Kepala Desa 


\section{REFERENSI}

Anderson, Neil T. Menjadi Gereja Pembuat Murid, Yogyakarta: Yayasan Gloria \& Katalis, 2016.

Antone, Hope S., Pendidikan Kristiani Kontekstual, Jakarta: BPK Gunung Mulia, 2010.

Bambangan, Malik, Dikat Misiologi, Banyumas, STT Diakonos, 2015.

---------, Diktat Sejarah Gereja Indonesia, Jakarta: SETIA, 2019.

----------, Malik, Gembala Sidang Sebagai Pengajar menurut Timotius dan Titus dalam Jurnal Phronesis Vol. 1 No. 1 Edisi Januari- Juni 2018, Jakarta: DELIMA, 2018.

Bilo, Dyulius Thomas, Tinjauan Filosofis Terhadap Pengembangan Kurikulum Pendidikan Agama Kristen dalam Jurnal Phronesis, Vol. 2 no.1 edisi Januari-Juni 2019, Jakarta: DELIMA, 2018.

Bonifacio, Joey, The Lego Principle: Memuridkan Bangsa Melalui Hubungan yang diBangun, Yogyakarta: Penerbit ANDI, 2013.

Borthwick, Paul, Great Commision, Great Compassion, Surabaya: Literatur Perkantas Jawa Timur, 2015.

Gladden, Steve, Memimpin Kelompok Kecil dengan Tujuan, Yogyakarta: Yayasan Gloria \& Katalis, 2015.

Harianto, GP., Teologi Misi, Yogyakarta: Penerbit ANDI, 2017.

Hutabarat, Herdy N., Mentoring dan Pemuridan, Bandung: Kalam Hidup, 2011.

MacCalum, Dennis \& Lowery, Jessica, Organic Dishipleship, Surabaya: Literatur Perkantas Jawa Timur, 2015.

Mangentang, Matheus, Visi dan Misi SETIA, Jakarta:DELIMA, 2016.

Morton, Scott, Pemuridan Untuk Semua Orang, Yoyakarta: Yayasan Gloria \& Katalis, 2011.

Novalia, Lisna, Integrasi Konteks Pendidikan Agama Kristen kedalam Pembelajaran. Jurnal Phronesis Vol. 3 No.1 edisi Januari -Juni 2020, Jakarta: DELIMA, 2020.

Salurante, Tony. The Glorious Effect Of God's Creation Through Baduy People. Jurnal Phronesis vol. 1, no. 1 Edisi Januari- Juni 2018, Jakarta: DELIMA, 2018.

Tung, Khoe Yao. Filsafat Pendidikan Kristen. Yogayakarta: Penderbit ANDI. 2013. 